\title{
Pengaruh Disiplin Kerja, Kompensasi dan Kepemimpinan terhadap Kinerja Karyawan pada PT. Sabas Indonesia
}

\section{Erika}

Universitas Prima Indonesia

erika.gohh@gmail.com

\section{Khomeiny Yunior}

Universitas Prima Indonesia

khomeinyyunior@gmail.com

\section{Felia Devita}

Universitas Prima Indonesia

feliadevita@yahoo.com

\section{Ivana Tamara \\ Universitas Prima Indonesia \\ ivana.tamaraz@gmail.com}

\section{Chelsea Herryanto}

Universitas Prima Indonesia

chel herryanto@hotmail.com

\begin{abstract}
Abstrak Tujuan dari dilakukannya penelitian ini adalah untuk mengetahui berkurangnya kinerja karyawan PT Sabas Indonesia yang disebabkan oleh Disiplin Kerja, Kompensasi dan Kepemimpinan. Adapun teori untuk mendukung penelitian yaitu dengan teori menurut para ahli yang berkaitan dengan Disiplin Kerja, Kompensasi dan Kepemimpinan. 128 orang karyawan digunakan sebagai populasi dan 97 karyawan digunakan sebagai sampel yang di dapat dengan menggunakan rumus Slovin dalam penelitian ini. Untuk uji validitas dan reliabilitas dilakukan pada PT Sabas Indonesia dengan menggunakan 30 pekerjanya. Metode pengumpulan data dengan wawancara, pembagian kuesioner dan studi dokumentasi. Model analisis yang digunakan adalah model analisis regresi linier berganda, koefisien determinasi pengujian secara simultan (Uji-F) dan secara parsial (Uji-t). Hasil penelitian menunjukkan Disiplin Kerja, Kompensasi dan Kepemimpinan secara simultan dan parsial berpengaruh signifikan terhadap kinerja karyawan dengan nilai koefisien determinasi sebesar $18,6 \%$ dan sisanya sebesar $81,4 \%$ merupakan pengaruh dari variabel independen lain yang tidak diteliti dalam penelitian ini seperti komitment organisasi, rekrutmen, dll.
\end{abstract}

Kata Kunci Disiplin Kerja, Kompensasi, Kepemimpinan, Kinerja Karyawan

\section{PENDAHULUAN}

Ketersediaan bahan makanan selain dari bahan makanan nabati ada juga bahan makanan hewani, dimana Indonesia juga sebagian besar penduduk mengkonsumsi jenis bahan makanan hewani tersebut. Untuk menunjang produksi bahan makanan hewani, maka selain makanan alami tersebut juga dibutuhkan bahan makanan tambahan seperti pakan ternak untuk dapat memproduksi bahan makanan hewani lebih cepat dan hewan lebih sehat. Industri pakan ternak memiliki peran besar dalam mendukung industri peternakan di Indonesia untuk penyediaan 
konsumsi bahan makanan hewani. PT. Sabas Indonesia merupakan salah satu perusahaan yang bergerak dalam industri pakan ternak dengan produk pakan unggas dan perikanan di Kota Medan, Sumatera Utara didirikan pada tahun 2011. PT. Sabas Indonesia berharap memiliki keuntungan dari hasil produktifitas kinerja mereka.

Kinerja karyawan adalah hasil kerja secara kualitas maupun kuantitas yang dapat dicapai oleh seorang karyawan dalam melaksanakan tugasnya sesuai dengan tanggung jawab yang diberikan kepadanya guna mecapai tujuan organisasi. PT. Sabas Indonesia mengalami penurunan produktivitas kinerja karyawan yang disebabkan oleh beberapa faktor seperti disiplin kerja, kompensasi dan kepemimpinan.

Disiplin kerja merupakan sikap menghormati, menghargai, dan taat terhadap peraturan yang berlaku di dalam suatu organisasi. Karyawan pada PT. Sabas Indonesia memiliki kesadaran yang kurang dalam menaati peraturan. Hal ini dapat dilihat dari adanya penurunan kinerja karyawan.

Kompensasi adalah imbalan yang diterima oleh seseorang atas hasil kerja yang dicapai. PT. Sabas Indonesia kurang memberikan kompensasi atas hasil kinerja karyawannya yang ditunjukan dengan adanya perubahan kualitas kerja karyawan.

Kepemimpinan merupakan kemampuan seseorang untuk mempengaruhi orang lain agar bekerja mencapai tujuan organisasi. Pada PT. Sabas Indonesia, ditemukan kurangnya intensitas bertemu antara pimpinan dengan karyawan, sehingga mengakibatkan kurangnya pengawasan dari pimpinan terhadap pekerjaan yang dilaksanakan oleh karyawan.

\section{LANDASAN TEORI}

\subsection{Pengaruh Disiplin Kerja terhadap Kinerja Karyawan}

Menurut Indah Puji Hartatik (2014:182) Disiplin merupakan suatu keadaan tertentu dimana orang-orang yang tergabung dalam organisasi tunduk pada peraturan-peraturan yang ada dengan rasa senang hati. Menurut Hasibuan (2016:198) Kedisiplinan merupakan fungsi MSDM yang terpenting untuk mengukur/mengetahui apakah fungsi-fungsi MSDM lainnya secara keseluruhan telah dilaksanakan dengan baik atau tidak. Menurut R. Supomo dan Eti Nurhayati (2018:134) Disiplin merupakan alat yang digunakan para manajer untuk berkomunikasi dengan karyawan agar mereka bersedia untuk mengubah suatu perilaku sebagai upaya untuk meningkatkan kesadaran dan kesediaan seseorang menaati semua peraturan dan norma organisasi yang berlaku.

Berdasarkan pengertian diatas dapat disimpulkan bahwa disiplin kerja merupakan alat yang digunakan para manjer, agar karyawan mau menaati akan semua peraturan yang berlaku.

\subsection{Pengaruh Kompensasi terhadap Kinerja Karyawan}

Menurut Edison, Anwar dan Komariyah (2016:154) Kompensasi adalah sesuatu yang diterima karyawan atau jasa yang mereka sumbangkan pada pekerjaannya. Mereka menyumbangkan apa yang menurut mereka berharga baik tenaga maupun pengetahuan yang dimiliki. Menurut Wibowo (2016:271) Kompensasi adalah jumlah paket yang ditawarkan organisasi kepada pekerja sebagai imbalan atas penggunaan tenaga kerjanya. Menurut Notoatmojo (2018:142) Kompensasi adalah segala sesuatu yang diterima oleh karyaawan sebagai balas jasa untuk kerja atau pengabdian mereka.

Berdasarkan pengertian diatas dapat disimpulkan bahwa kompensasi merupakan suatu bentuk balas jasa yang diberikan perusahaan kepada karyawan bisa dalam bentuk materi atau non materi.

\subsection{Pengaruh Kepemimpinan terhadap Kinerja Karyawan}

Menurut Sutrisno (2012:216) Kepemimpinan adalah gejala universal yang ada pada setiap kelompok manusia sebagai sebuah sistem sosial, mulai dari kelompok kecil yang terdiri dari beberapa orang sampai pada kelompok besar yang dinamakan bangsa. Menurut Kartono 
(2013:187), kepemimpinan ialah satu bentuk dominasi yang didasari oleh kapabilitas/kemampuan pribadi, yaitu mampu mendorong dan mengajak oraang lain untuk berbuat sesuatu guna mencapai tujuan bersama. Menurut Herlambang (2014:93) Kepemimpinan adalah kemapuan untuk mempengaruhi perubahan perilaku orang lain, baik langsung maupun tidak langsung.

Berdasarkan pengertian diatas dapat disimpulkan bahwa kepemimpinan adalah cara seseorang dalam upaya membina dan mempengaruhi seseorang atau kelompok guna mencapai tujuan organisasi.

\subsection{Kerangka Konseptual}

Kerangka konseptual dapat digambarkan sebagai berikut :

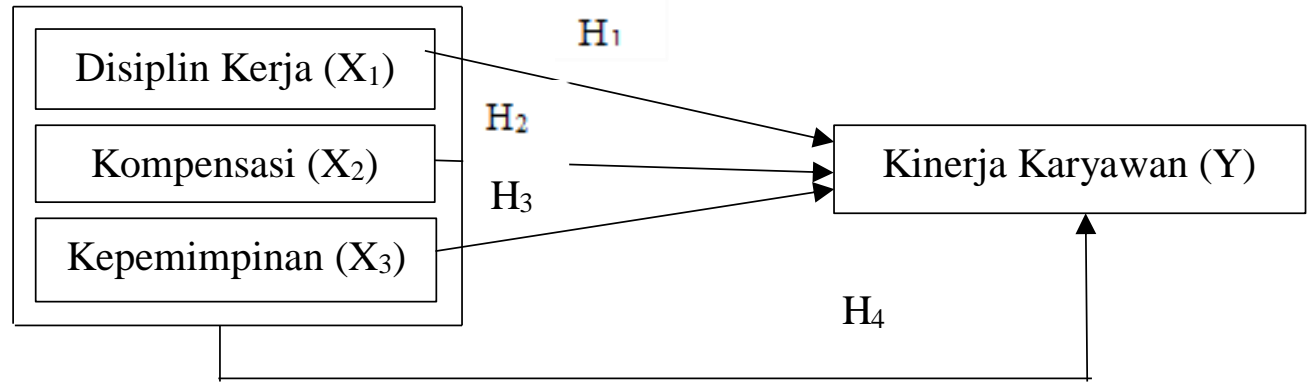

Gambar II.1.

Kerangka Konseptual

\subsection{Hipotesis}

Hipotesis dari penelitian diatas

$\mathrm{H}_{1}$ : Disiplin Kerja berpengaruh terhadap Kinerja Karyawan pada PT. Sabas Indonesia.

$\mathrm{H}_{2}$ : Kompensasi berpengaruh terhadap Kinerja Karyawan pada PT. Sabas Indonesia.

$\mathrm{H}_{3}$ : Kepemimpinan berpengaruh terhadap Kinerja Karyawan pada PT. Sabas

Indonesia.

$\mathrm{H}_{4}$ : Disiplin Kerja, Kompensasi, dan Kepemimpinan berpengaruh terhadap Kinerja

Karyawan pada PT.Sabas Indonesia.

\section{METODOLOGI PENELITIAN}

Metode penelitian yang peneliti gunakan adalah metode penelitian kuantitatif. Jenis penelitian ini merupakan jenis penelitian deskriptif kuantitatif. Sifat penelitian ini adalah deskriptif explanatory.

Peneliti mengambil populasi sampel sebanyak 128 karyawan dari bulan Januari sampai Desember 2020. Teknik sampling yang digunakan adalah teknik simple random sampling. Menurut Sugiyono (2017:82) simple random sampling adalah teknik pengambilan sampel dari anggota populasi yang dilakukan secara acak tanpa memperhatikan strata yang ada dalam populasi itu. Untuk menentukan jumlah sampel, peneliti menggunakan rumus Slovin yaitu : $\mathrm{Ne}^{2}$

$$
\begin{gathered}
n=\frac{N}{1+\mathrm{Ne}^{2}} \\
n=\frac{128}{1+128(0,05)^{2}} \\
n=97 \text { karyawan }
\end{gathered}
$$


$\mathrm{n}=$ Ukuran Sampel

$\mathrm{N}=$ Populasi

$\mathrm{e}=$ Presentasi kelonggaran ketidakterikatan karena kesalahan pengambilan sampel yang dinginkan

Jumlah sampel dalam penelitian ini adalah sebanyak 97 karyawan. Untuk pengujian validitas dan reliabilitas sebanyak 30 karyawan di luar sampel penelitian.

\section{HASIL PENELITIAN DAN PEMBAHASAN}

\section{IV.1. Hasil Penelitian}

\begin{tabular}{|l|c|c|c|c|c|}
\hline & N & Minimum & Maximum & Mean & $\begin{array}{c}\text { Std. } \\
\text { Deviation }\end{array}$ \\
\hline Disiplin_Kerja & 97 & 9,00 & 26,00 & 17,9485 & 3,91677 \\
\hline Kompensasi & 97 & 13,00 & 35,00 & 26,8660 & 4,12974 \\
\hline Kepemimpinan & 97 & 16,00 & 44,00 & 29,9175 & 7,47450 \\
\hline Kinerja_Karyawan & 97 & 18,00 & 40,00 & 30,4948 & 4,56464 \\
\hline Valid N (listwise) & 97 & & & & \\
\hline
\end{tabular}

Sumber : Hasil pengolahan data menggunakan SPSS, 2021

Tabel IV.1

Dari Tabel IV.1 Hasil Uji Descriptive Statistics

akan adalah sebanyak 61 orang yang merupakan karyawan PT Sabas Indonesia, variabel Disiplin Kerja mempunyai nilai minimum 9 dan nilai maksimum 26 dengan rata - rata 17,9485 dan standar deviasi 3,91677. Variabel Kompensasi mempunyai nilai minimum 13 dan nilai maksimum 35 dengan rata - rata 26,866 dan standar deviasi 4,12974. Variabel Kepemimpinan mempunyai nilai minimum 16 dan nilai maksimum 44 dengan nilai rata - rata 29,9175 dan standar deviasi 7,4745. Variabel Kinerja Karyawan mempunyai nilai minimum 18 dan nilai maksimum 40 dengan nilai rata - rata 30,4948 dan standar deviasi 4,56464.

\section{IV.2. Uji Asumsi Klasik \\ IV.2.1. Uji Normalitas}

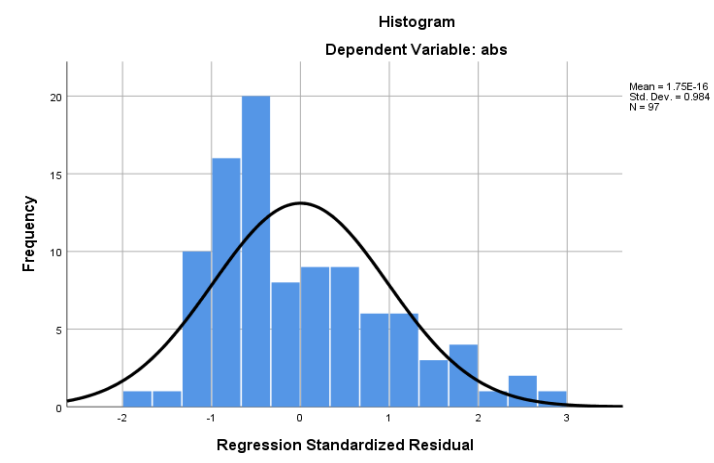

Sumber : Hasil pengolahan data menggunakan SPSS, 2021

Gambar IV.1 Grafik Histogram

Gambar IV.1 di atas, terlihat bahwa garis berbentuk lonceng, tidak melenceng ke kiri maupun ke kanan. Hal ini menunjukkan bahwa data berdistribusi normal dan memenuhi asumsi normalitas. 


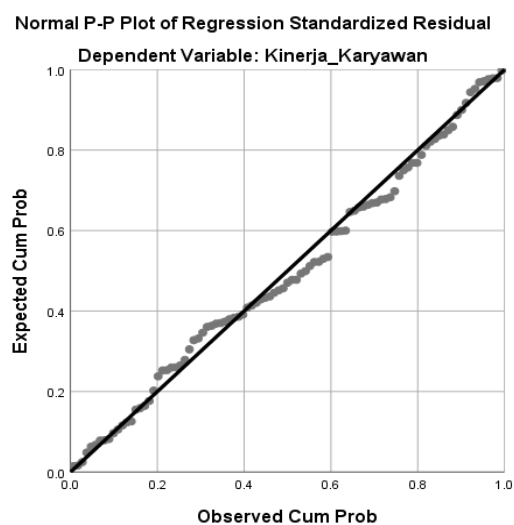

Sumber : Hasil pengolahan data menggunakan SPSS, 2021

Gambar IV.2 Grafik Probability Plot

Gambar IV.2 menunjukkan bahwa data menyebar disekitar garis diagonal dan mengikuti arah garis diagonalnya. Hal ini menjelaskan bahwa data yang diregresi dalam penelitian ini berdistribusi normal.

\begin{tabular}{|c|c|c|}
\hline & & $\begin{array}{l}\text { Unstandardized } \\
\text { Residual }\end{array}$ \\
\hline $\mathrm{N}$ & & 97 \\
\hline Normal & Mean & 0,0000000 \\
\hline Parameters ${ }^{\mathrm{a}, \mathrm{b}}$ & $\begin{array}{l}\text { Std. } \\
\text { Deviation }\end{array}$ & 4,05320467 \\
\hline Most & Absolute & 0,063 \\
\hline Extreme & Positive & 0,063 \\
\hline Differences & Negative & $-0,049$ \\
\hline Test Stat & & 0,063 \\
\hline Asymp. & ig. (2-tailed) & $.200^{\mathrm{c}, \mathrm{d}}$ \\
\hline
\end{tabular}

\section{Tabel IV.2}

Hasil Uji One-Sample Kolmogorov-Smirnov Test

a. Test distribution is Normal.

b. Calculated from data.

c. Lilliefors Significance Correction.

d. This is a lower bound of the true significance.

Tabel IV.2 tersebut menunjukkan bahwa besarnya nilai K-S yang diperoleh adalah sebesar 0.051 dengan signifikan 0.200 , karena nilai signifikan yang diperoleh lebih besar dari 0.05 maka ini berarti $\mathrm{H}_{1}$ diterima, artinya data residual berdistribusi normal.

\section{IV.2.2. Uji Multikolinearitas}

Tabel IV.3. Hasil Uji Multikolinearitas

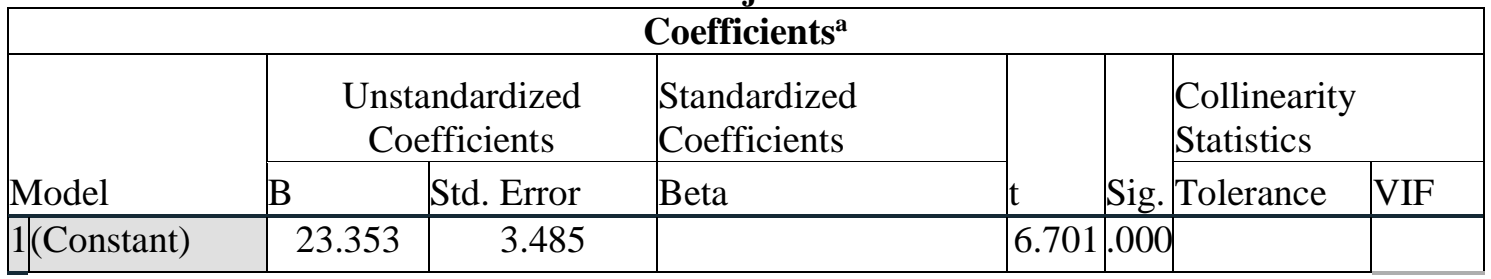




\begin{tabular}{|l|c|c|c|c|c|c|c|}
\hline Disiplin_Kerja & .322 & .111 & .276 & 2.907 & .005 & .940 & 1.064 \\
\hline Kompensasi & .224 & .105 & .203 & 2.134 & .036 & .941 & 1.063 \\
\hline Kepemimpinan & -.155 & .056 & -.254 & - & .007 & .997 & 1.003 \\
\hline
\end{tabular}

a. Dependent Variable: Kinerja_Karyawan

Sumber: Hasil pengolahan data mengggunakan SPSS, 2021

Berdasarkan perhitungan nilai Tolerance juga menunjukkan tidak ada variabel independen yang memiliki nilai Tolerance lebih kecil dari 0,10 dan Hasil perhitungan nilai Variance Inflation Factor (VIF) juga menunjukkan hal yang sama tidak ada satu variabel independen yang memiliki nilai VIF lebih dari 10. Jadi dapat disimpulkan bahwa tidak ada multikolonieritas antar variabel independen dalam model regresi.

\section{IV.2.3. Uji Heteroskedastisitas}

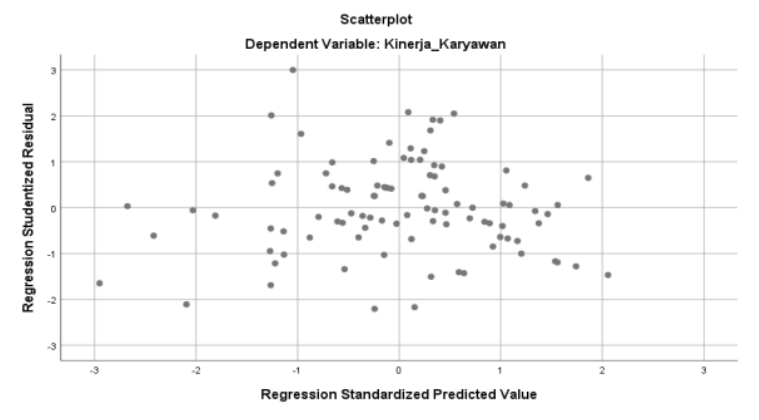

\section{Gambar IV.3. Hasil Pengujian Heteroskedastisitas}

Pada Gambar IV.3, terlihat titik yang menyebar yang tidak membentuk pola - pola tertentu dan tersebar baik diatas dan di bawah angka 0 pada sumbu Y dan berdasarkan gambar tersebut maka tidak terjadi heteroskedastisitas sehingga model regresi layak dipakai.

Tabel IV.4. Hasil Uji Glejser

\begin{tabular}{|c|c|c|c|c|c|c|c|c|}
\hline \multicolumn{9}{|c|}{ Coefficients $^{\mathbf{a}}$} \\
\hline & & \multicolumn{2}{|c|}{$\begin{array}{l}\text { Unstandardized } \\
\text { Coefficients }\end{array}$} & \multirow{2}{*}{$\begin{array}{c}\begin{array}{c}\text { Standardized } \\
\text { Coefficients }\end{array} \\
\text { Beta } \\
\end{array}$} & \multirow[t]{2}{*}{$t$} & \multirow[t]{2}{*}{ Sig. } & \multicolumn{2}{|c|}{$\begin{array}{l}\text { Collinearity } \\
\text { Statistics }\end{array}$} \\
\hline \multicolumn{2}{|c|}{ Model } & $\mathrm{B}$ & $\begin{array}{l}\text { Std. } \\
\text { Error }\end{array}$ & & & & Tolerance & VIF \\
\hline \multirow[t]{4}{*}{1} & (Constant) & 6.247 & 2.159 & & 2.894 & .005 & & \\
\hline & Disiplin_Kerja & -.015 & .069 & -.023 & -.217 & .828 & .940 & 1.064 \\
\hline & Kompensasi & -.101 & .065 & -.163 & -1.550 & .125 & .941 & 1.063 \\
\hline & Kepemimpinan & -.005 & .035 & -.013 & -.132 & .896 & .997 & 1.003 \\
\hline
\end{tabular}

a. Dependent Variable: abs

Sumber: Hasil pengolahan data mengggunakan SPSS, 2021

Hasil tampilan output SPSS Tabel IV.4, hasil uji heteroskedastisitas, nilai koefisien regresi dari masing-masing variabel bebas dalam model regresi nilai absolut residual ini tidak signifikan secara statistik (sig>0,05), maka dapat disimpulkan tidak terjadi heteroskedastisitas.

\section{IV.3. Analisis Regresi Linear Berganda}


Tabel IV.5. Hasil Analisis Regresi Linear Berganda

\begin{tabular}{|c|c|c|c|c|c|c|c|c|}
\hline \multicolumn{9}{|c|}{ Coefficients $^{\mathbf{a}}$} \\
\hline \multirow{2}{*}{\multicolumn{2}{|c|}{ Model }} & \multicolumn{2}{|c|}{$\begin{array}{l}\text { Unstandardized } \\
\text { Coefficients }\end{array}$} & \multirow{2}{*}{\begin{tabular}{|l|}
$\begin{array}{l}\text { Standardized } \\
\text { Coefficients }\end{array}$ \\
Beta
\end{tabular}} & \multirow{2}{*}{ t } & \multirow[b]{2}{*}{ Sig. } & \multicolumn{2}{|c|}{$\begin{array}{l}\text { Collinearity } \\
\text { Statistics }\end{array}$} \\
\hline & & B & Std. Error & & & & Tolerance & VIF \\
\hline \multirow[t]{4}{*}{1} & (Constant) & 23.353 & 3.485 & & 6.701 & .000 & & \\
\hline & Disiplin_Kerja & .322 & .111 & .276 & 2.907 & .005 & .940 & 1.064 \\
\hline & Kompensasi & .224 & .105 & .203 & 2.134 & .036 & .941 & 1.063 \\
\hline & Kepemimpinan & -155 & .056 & -.254 & -2.759 & .007 & .997 & 1.003 \\
\hline
\end{tabular}

a. Dependent Variable: Kinerja_Karyawan

Sumber: Hasil pengolahan data mengggunakan SPSS, 2021

Kinerja Karyawan $=23,353+0,322$ Disiplin Kerja + 0,224 Kompensasi $-0,155$ Kepemimpinan

Persamaan regresi tersebut mempunyai makna sebagai berikut

1. Nilai konstanta a sebesar 23,353 artinya bahwa jika tidak terdapat variabel Disiplin Kerja $\left(\mathrm{X}_{1}\right)$, Kompensasi $\left(\mathrm{X}_{2}\right)$ dan Kepemimpinan $\left(\mathrm{X}_{3}\right)=0$ maka Kinerja Karyawan akan bernilai sebesar 23,353 satuan.

2. Variabel Disiplin Kerja $\left(\mathrm{X}_{1}\right)$ sebesar 0,322 yang artinya bahwa setiap kenaikkan variabel Disiplin Kerja sebesar 1 satuan, maka nilai pada Kinerja Karyawan akan meningkat 0,322 satuan dengan asumsi bahwa variabel yang lain tetap.

3. Variabel Kompensasi $\left(\mathrm{X}_{2}\right)$ sebesar 0,224 yang artinya bahwa setiap kenaikan variabel Kompensasi sebesar 1 satuan, maka nilai pada Kinerja Karyawan akan naik 0,224 satuan dengan asumsi bahwa variabel yang lain tetap.

4. Variabel Kepemimpinan $\left(X_{3}\right)$ sebesar 0,155 yang artinya bahwa setiap kenaikan variabel Kepemimpinan sebesar 1 satuan, maka nilai pada Kinerja Karyawan akan naik 0,155 satuan dengan asumsi bahwa variabel yang lain tetap.

\section{IV.4. Koefisien Determinasi Hipotesis}

Tabel IV.6. Hasil Analisis Koefisien Determinasi Hipotesis

\begin{tabular}{|l|l|l|l|l|}
\hline \multicolumn{5}{|c|}{ Model Summary $^{\mathbf{b}}$} \\
\hline Model & $\mathrm{R}$ & R Square & $\begin{array}{l}\text { Adjusted } \\
\text { Square }\end{array}$ & $\begin{array}{l}\text { R Std. Error of the } \\
\text { Estimate }\end{array}$ \\
\hline $1 \quad$ & $.460^{\mathrm{a}}$ & .212 & .186 & 4.11806 \\
\hline $\begin{array}{l}\text { a. Predictors: } \\
\text { Disiplin_Kerja }\end{array}$ & (Constant), Kepemimpinan, Kompensasi, \\
\hline
\end{tabular}

Sumber: Hasil pengolahan data mengggunakan SPSS, 2021

Pada tabel IV.6 menjelaskan besarnya nilai korelasi atau hubungan (R) antara Disiplin Kerja $\left(\mathrm{X}_{1}\right)$, Kompensasi $\left(\mathrm{X}_{2}\right)$ dan Kepemimpinan $\left(\mathrm{X}_{3}\right)$ dengan Kinerja Karyawan (Y)yaitu pada Adjusted $R$ Square sebesar 0.186 yang mengandung pengertian bahwa pengaruh variabel bebas (Disiplin Kerja, Kompensasi dan Disiplin Kerja) terhadap variabel terikat (Kinerja Karyawan) adalah sebesar $18,6 \%$. Hal ini menunjukkan bahwa variabel independen hanya mampu menjelaskan variasi perubahan variabel dependen sebesar $18,6 \%$ sedangkan sisanya sebesar 
81,4\% dijelaskan oleh variabel lain (komitment organisasi, rekrutmen, dll) yang tidak digunakan dalam penelitian ini.

\section{IV.5 Pengujian Hipotesis Secara Simultan (Uji F)}

Tabel IV.7. Hasil Pengujian Hipotesis Secara Simultan

\begin{tabular}{|l|l|l|l|l|l|l|}
\hline \multicolumn{7}{|c|}{ ANOVA $^{\text {a }}$} \\
\hline Model & Sum of Squares & df & Mean Square & F & Sig. \\
\hline \multirow{4}{*}{1} & Regression & 423.114 & 3 & 141.038 & 8.317 & $.000^{\mathrm{b}}$ \\
\cline { 2 - 7 } & Residual & 1577.133 & 93 & 16.958 & & \\
\cline { 2 - 7 } & Total & 2000.247 & 96 & & & \\
\hline a. Dependent Variable: Kinerja_Karyawan \\
b. Predictors: (Constant), Kepemimpinan, Kompensasi, Disiplin_Kerja \\
\hline
\end{tabular}

Sumber: Hasil pengolahan data mengggunakan SPSS, 2021

Pada Tabel IV.7 bahwa hasil output terlihat bahwa F hitung > F tabel 8,3175 >2,77), maka $\mathrm{H}_{1}$ diterima, artinya dikarenakan F hitung lebih besar dari F tabel dan Signigfikan tidak melebihi 0.05 maka dapat disimpulkan, secara signifikan ada pengaruh positif simultan antara Disiplin Kerja, Kompensasi dan Kepemimpinan terhadap Kinerja Karyawan PT Sabas Indonesia.

\section{IV.6 Pengujian Hipotesis Secara Parsial (Uji t)}

Tabel IV.8. Hasil Pengujian Hipotesis Secara Parsial

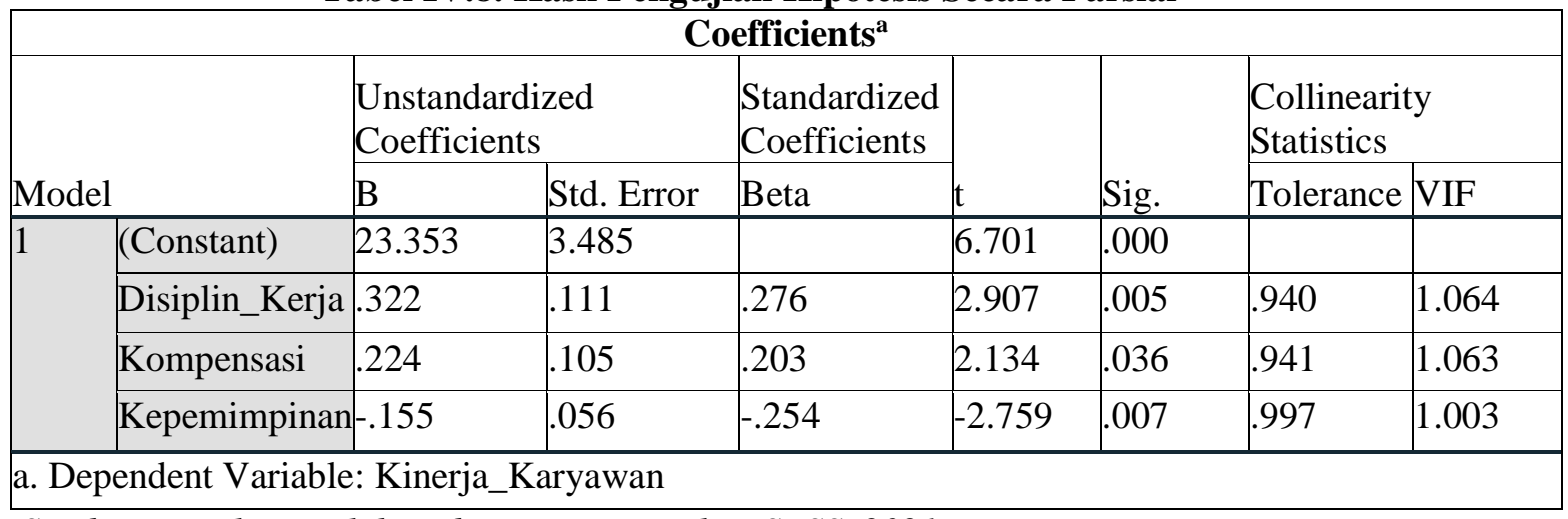

Sumber: Hasil pengolahan data mengggunakan SPSS, 2021 berikut:

Pada tabel IV.8 hasil pengujian statistik dengan SPSS untuk uji parsial adalah sebagai

- Pada variabel $X_{1}$ (Disiplin Kerja) diperoleh nilai t hitung $=2,907$, kemudian $t$ tabelnya adalah dengan $\mathrm{df}=94$ taraf signifikansi $5 \%(0,05)$ uji dua sisi adalah 2,00247. Oleh karena nilai $\mathrm{t}$ hitung $>\mathrm{t}$ tabel $(2,907>1,98552)$ dan signifikian $0,005<0,05$ maka $\mathrm{H}_{0}$ ditolak dan $\mathrm{H}_{1}$ diterima, Disiplin Kerja secara parsial berpengaruh positif dan signifikan terhadap Kinerja Karyawan PT Sabas Indonesia.

- $\quad$ Pada Variabel $\mathrm{X}_{2}$ (Kompensasi) diperoleh nilai thitung $=2,134$, $\mathrm{t}$ hitung $>\mathrm{t}$ tabel $(2,907$ $>1,98552$ ), dan signifikan $0.036<0.05$. maka $\mathrm{H}_{0}$ ditolak dan $\mathrm{H}_{1}$ diterima, artinya Kompensasi secara parsial berpengaruh positif dan signifikan terhadap Kinerja Karyawan PT Sabas Indonesia.

- Pada Variabel $\mathrm{X}_{3}$ (Kepemimpinan) diperoleh nilai -thitung $=-2,759$, $\mathrm{t}$ hitung $<-\mathrm{t}$ tabel ($2,759<1,98552$ ), dan signifikan $0.007<0.05$. maka $\mathrm{H}_{0}$ ditolak dan $\mathrm{H}_{1}$ diterima, artinya Kepemimpinan secara parsial berpengaruh positif dan signifikan terhadap Kinerja Karyawan PT Sabas Indonesia. 


\section{IV.7 Pembahasan}

\section{IV.7.1 Pengaruh Disiplin Kerja terhadap Kinerja Karyawan}

Hasil penelitian menunjukkan bahwa nilai $\mathrm{t}$ hitung $>\mathrm{t}$ tabel $(2,907>1,98552)$ dan signifikian $0,005<0,05$ sehingga sehingga dapat disimpulkan $\mathrm{H}_{1}$ diterima. Hal ini mengindikasikan bahwa disiplin kerja berpengaruh positif dan signifikan terhadap kinerja karyawan pada PT Sabas Indonesia.

Hal ini didukung oleh Indah Puji Hartatik (2014:182) yang menyatakan Disiplin merupakan suatu keadaan tertentu dimana orang-orang yang tergabung dalam organisasi tunduk pada peraturan-peraturan yang ada dengan rasa senang hati.

Disiplin yang baik akan menghasilkan kinerja yang baik diman karyawan akan lebih maksimal dalam mengerjakan pekerjaan dan juga tangggung jawab yang di berikan perusahaan kepada karyawan tersebut. Selain itu disiplin kerja juga akan memberikan dampak yang positif dalam hasil kerja karyawan tersebut dimana semakin disiplin karyawan tersebut maka dia akan bekerja sesuai dengan SOP yang ada pada perusahaan sehingga akan menciptakan hasil kerja yang baik dan akan berujung pada kinerja karyawan yang semakin baik.

\section{IV.7.2 Pengaruh Kompensasi terhadap Kinerja Karyawan}

Hasil penelitian menunjukkan bahwa nilai thitung $=2,134$, $\mathrm{t}$ hitung $>\mathrm{t}$ tabel $(2,907>$ 1,98552), dan signifikan $0.036<0.05$ sehingga dapat disimpulkan $\mathrm{H}_{2}$ diterima. Hal ini mengindikasikan bahwa kompensasi berpengaruh positif dan signifikan terhadap kinerja karyawan pada PT Sabas Indonesia.

Hal ini didukung oleh Edison, Anwar dan Komariyah (2016:154) Kompensasi adalah sesuatu yang diterima karyawan atau jasa yang mereka sumbangkan pada pekerjaannya. Mereka menyumbangkan apa yang menurut mereka berharga baik tenaga maupun pengetahuan yang dimiliki.

Hal ini di sebabkan karena kebutuhan hidup dan gaya hidup yang semakin tinggi yang mendorong karyawan menyukai gaji yang tinggi, selain itu karyawan akan merasa perusahaan memberikan apresiasi terhadap kinerja karyawan tersebut. Penurunan kinerja karyawan dapat terjadi karena adanya gaji yang di berikan di rasa karyawan tidak memenuhi keinginan mereka.

\section{IV.7.3 Pengaruh Kepemimpinan terhadap Kinerja Karyawan}

Hasil penelitian menunjukkan bahwa nilai -thitung $=-2,759$, t hitung $<-t$ tabel $(-2,759<$ 1,98552), dan signifikan $0.007<0.05$ sehingga dapat disimpulkan $\mathrm{H}_{3}$ diterima. Hal ini mengindikasikan bahwa kepemimpinan berpengaruh negatif dan signifikan terhadap kinerja karyawan pada PT Sabas Indonesia.

Hal ini didukung oleh Sutrisno (2012:216) Kepemimpinan adalah gejala universal yang ada pada setiap kelompok manusia sebagai sebuah sistem sosial, mulai dari kelompok kecil yang terdiri dari beberapa orang sampai pada kelompok besar yang dinamakan bangsa.

Kepemimpinan adalah individu yang mampu mempengaruh perilaku orang lain tanpa harus mengandalkan kekerasan. Agar dapat meningkatkan kinerja karyawan, pemimpin di perusahaan butuh mengubah perilaku atau gaya kepemimpinan yang di buatnya dengan cara mendengarkan keluhan dan juga saran dari bawahannya, memberikan sanksi sesuai dengan kebijakan perusahaan, membantu pekerjaan bawahannya, memberikan arahan yang tepat agar karyawan dapat bekerja dengan cepat dan mengasilkan pekerjaan yang lebih baik.

\section{Kesimpulan}

Kesimpulan yang diambil dari variabel Disiplin Kerja adalah hasil t hitung $>t$ tabel $(2,907$ $>1,98552$ ) dan signifikian 0,005 < 0,05 maka variable Disiplin Kerja berpengaruh negatif dan signifikan terhadap Kinerja Karyawan. Dan variabel Kompensasi dengan hasil t hitung $>\mathrm{t}$ tabel $(2,907>1,98552)$ dan signifikan $0.036<0.05$ maka variable Kompensasi berpengaruh positif dan signifikan terhadap Kinerja Karyawan. Variabel Kepemimpinan dengan hasil $t$ hitung $<-t$ 
tabel $(-2,759<1,98552)$, dan signifikan $0.007<0.05$ maka variabel kepemimpinan berpengaruh positif dan signifikan terhadap Kinerja Karyawan. Maka semua dapat disimpulkan bahwa Variabel Disiplin Kerja $\left(\mathrm{X}_{1}\right)$, Kompensasi $\left(\mathrm{X}_{2}\right)$, dan Kepemimpinan $\left(\mathrm{X}_{3}\right)$ dengan hasil F hitung > F tabel $(8,3175>2,77)$ secara simultan berpengaruh terhadap Kinerja Karyawan.

\section{DAFTAR PUSTAKA}

Abdillah, Arief Chaidir. 2011. Pengaruh Kepemimpinan, Stres Kerja, Disiplin Kerja dan Kompensasi dengan Kinerja Pegawai di Kantor Pelayanan Pajak Pratama Boyolali. Jurnal.

Edison, Anwar, dan Komariyah. 2016. Manajemen Sumber Daya Manusia. Bandung : Alfabeta Ghozali, Imam. 2013. Aplikasi Analisis Multivariate dengan Program IBM SPSS 21 Update PLS Regresi. Semarang : Badan Penerbit Universitas Diponegoro.

Ghozali, Imam. 2016. Aplikasi Analisis Multivariate dengan Program IBM SPSS 23 Update PLS Regresi. Semarang : Universitas Diponegoro.

Hartatik, Indah Puji. 2014. Buku Praktis Mengembangkan SDM. Yogyakarta : Laksana.

Hasibuan, M.S.P. 2016. Manajemen Sumber Daya Manusia. Edisi Revisi. Jakarta : Bumi Aksara.

Herlambang, Susatyo. 2014. Perilaku Organisasi. Yogyakarta : Pustaka Baru.

Nainggolan, Michael Stefen. 2020. Pengaruh Kepemimpinan, Motivasi dan Disiplin Kerja terhadap Kinerja Karyawan pada PT. PP London Sumatera, Tbk, Batu Lokong, Galang, BG. POM Kabupaten Deli Serdang, Sumatera Utara. Jurnal.

Kartono, Kartini. 2013. Pemimpin dan Kepemimpinan: Apakah Kepemimpinan Abnormal Itu? Edisi Pertama. Jakarta : PT. Rajawali

Kurniawan, Robert dan Budi Yuniarto. 2016. Analisis Regresi: Dasar dan Penerapannya dengan $\boldsymbol{R}$. Jakarta : Kencana.

Moeheriono. 2012. Pengukuran Kinerja Berbasis Kompetensi. Jakarta : PT Raja Grafindo Persada

Notoatmodjo, Soekidjo. 2018. Pengembangan Sumber Daya Manusia. Jakarta : Rineka Cipta.

Rumondor, Rommy Beno, Altje Tumbel, Jantje L. Sepang. 2016. Pengaruh Kepemimpinan, Motivasi, dan Disiplin Kerja terhadap Kinerja Pegawai pada Kanwil Ditjen Kekayaan Negara Suluttenggomalut. Jurnal.

Sujarweni, V. Wiratna. 2014. Metode Penelitian: Lengkap, Praktis, dan Mudah Dipahami. Yogyakarta : Pustaka Baru Press.

Supomo, Eti Nurhayati. 2018. Manajemen Sumber Daya Manusia. Bandung : Yrama Widya

Sutrisno, H.E. 2012. Manajemen Sumber Daya Manusia. Edisi Pertama. Jakarta : Prenadamedia Group.

Wibowo. 2016. Manajemen Kinerja. Edisi Kelima. Jakarta : PT. Rajawali Pers. 